\title{
AAN position statement: Ethical issues in clinical research in neurology
}

\author{
Benjamin Tolchin, MD, MS, * Robin Conwit, MD, * Leon G. Epstein, MD, and James A. Russell, DO, MS, on behalf \\ of the Ethics, Law, and Humanities Committee, a joint committee of the American Academy of Neurology, \\ American Neurological Association, and Child Neurology Society
}

Neurology ${ }^{\circledR}$ 2020;94:661-669. doi:10.1212/WNL.0000000000009241

\author{
Correspondence \\ Dr. Tolchin \\ benjamin.tolchin@yale.edu
}

\begin{abstract}
This update to the American Academy of Neurology's 1998 position statement endeavors to provide guidance for the consistent ethical conduct and review of neurologic research involving human participants. It does so by outlining a widely used ethical framework of 7 principles derived from the foundational documents of modern bioethics, including the Nuremberg Code, the World Medical Association's Declaration of Helsinki, the Belmont Report, and the US Department of Health and Human Service's Common Rule. The position statement then applies this principle-based framework to analyze and produce recommendations for the management of common and important ethical issues encountered in neurologic clinical research. These include institutional review board oversight, equitable research participant inclusion, cognitive impairment in research participants, international studies, the replication crisis, and genetic testing and modification.
\end{abstract}

\section{Introduction}

Clinical research entails work with human participants intended primarily to develop generalizable knowledge about health and disease. It includes both interventional studies such as clinical trials and also observational studies. Ethical considerations in clinical research differ from medical decisionmaking in the individual patient. In clinical care, ethical analysis is simplified as both benefit and risk are borne primarily by the individual patient based upon his or her own value system, potentially without external influence. In clinical research involving human participants, the risk is largely borne by the research participant whereas, the potential benefits extend not only to that participant but also to the investigator and society at large. Therapeutic misconception - the belief that the primary goal of clinical research is direct benefit to participants rather than the production of generalizable knowledge-is common among participants and physicians. ${ }^{1}$ Clinical researchers, unlike health care providers, have dual and often divergent ethical obligations. Researchers have a duty to research participants but also to the society that funds, facilitates, and permits their research and to potential future beneficiaries of the knowledge derived from their studies. While clinical research has created benefits for patients and society, its history has also included a number of egregious ethical violations, both infamous and obscure. ${ }^{2-6}$

This revision to the American Academy of Neurology's (AAN) 1998 position statement ${ }^{7}$ endeavors to provide guidance to its members involved with research on human participants. It outlines a principle-based framework for analyzing some of the most important ethical challenges currently facing neuroscientists, and by doing so, mitigating the risk to human participants involved in clinical research.
AMERICAN ACADEMY OF NEUROLOGY

\footnotetext{
*These authors contributed equally to this work.

From the Comprehensive Epilepsy Center, Department of Neurology (B.T.), Yale University School of Medicine, New Haven, CT; Epilepsy Center of Excellence, Neurology Service (B.T.), VA Connecticut Healthcare System, West Haven; Division of Clinical Research (R.C.), National Institute of Neurological Disorders and Stroke, NIH, Bethesda, MD; Division of Neurology, Department of Pediatrics (L.G.E.), Northwestern University Feinberg School of Medicine, Chicago; Stanley Manne Children's Research Institute (L.G.E.), Ann \& Robert H. Lurie Children's Hospital of Chicago, IL; and Division of Neurology (J.A.R.), Lahey Hospital and Medical Center, Burlington, MA

Go to Neurology.org/N for full disclosures. Funding information and disclosures deemed relevant by the authors, if any, are provided at the end of the article.

This American Academy of Neurology position statement has been endorsed by the American Neurologic Association and the Child Neurology Society.
} 


\section{Glossary}

AAN = American Academy of Neurology; CIOMS = Council of International Organisations for Medical Sciences; DHHS = Department of Health and Human Service; EFIC = exception from informed consent; HIC = high-income country; ICHGCP = International Conference on Harmonisation of Technical Requirements for Registration of Pharmaceuticals for Human Use's Guideline for Good Clinical Practice; IRB = institutional review board; LMIC = low- and middle-income country; WMA $=$ World Medical Association.

\section{Ethical framework}

The foundation of modern clinical research ethics is the Nuremberg Code, developed during the trial of Nazi researchers in 1947; the Declaration of Helsinki, promulgated by the World Medical Association (WMA) in 1964 (with numerous subsequent revisions); and the Belmont Report, developed in 1978 in response to the Tuskegee Syphilis Study. The Belmont Report in particular establishes the distinction between clinical practice and research, proposes the principles of beneficence, autonomy, and justice that shape modern bioethical theory, and applies these ethical principles to informed consent, the assessment of risks and benefits in research, and the selection of research participants. The Nuremberg Code, the Declaration of Helsinki, and especially the Belmont Report together inform the US Department of Health and Human Service's (DHHS) Common Rule (45 CFR part 46), which sets the standards for federally funded research in the United States, and which is widely adopted by almost all academic institutions in the United States regardless of their reliance on federal funding.

One summary of the requirements found in these foundational documents is Ezekiel Emanuel's framework of 7 principles for the ethical analysis of research on human participants. ${ }^{8}$ For the purposes of this position statement, we will make use of these 7 principles as a practical and concise distillation of the fundamental ethical guidelines detailed at greater length in the Nuremberg Code, the Declaration of Helsinki, the Belmont Report, and the Common Rule. Principle-based analysis is helpful in focusing attention on common ethical problems, avoiding unintentional oversight of ethical vulnerabilities, and providing a common starting point for interdisciplinary discussion and debate. Emanuel's 7 principles have been widely accepted and utilized over the last decade and a half, and are explicitly endorsed and promulgated by the NIH., ${ }^{9,10}$ These 7 principles, derived from the foundational documents of research ethics, are social value, scientific validity, fair participant selection, favorable riskbenefit ratio, independent review, informed consent, and respect for participants (table). Addressing all 7 principles is necessary and sufficient for clinical research to be considered ethically permissible.

Social value is the requirement that a clinical study must have the potential to improve human health or meaningfully increase society's knowledge of human biology.
Scientific validity is the requirement that a study must use accepted scientific methodology to produce valid and reproducible results.

Fair participant selection is the requirement that study sites, populations, and participants be selected based primarily on scientific criteria and that vulnerable populations neither be targeted nor excluded in clinical studies.

Favorable risk-benefit ratio is the requirement that risks to participants be minimized and that potential benefits to participants and society be disproportionately greater than the risks to participants.

Independent review is the requirement that clinical studies be reviewed and approved by knowledgeable individuals unaffiliated with the research, traditionally by an institutional review board (IRB) or a part thereof.

Informed consent, the best-known principle of ethical clinical research, is the requirement that participants be accurately informed of and understand the purpose, risks, benefits, and alternatives of a clinical study, and that they make an uncoerced decision whether or not to participate.

Respect for participants is the requirement that both potential and enrolled participants be treated respectfully, with attention to and protection of their privacy and interests throughout the course of the study.

Together these 7 principles summarize the requirements of the Nuremberg Code, the Helsinki Declaration, the Belmont Report, and the Common Rule, allowing these requirements to be easily applied to the ethical evaluation of clinical research. The following sections provide principle-based ethical analysis and practical suggestions concerning some of the common ethical issues that clinical neuroscientists have encountered historically, are now facing, and may anticipate in the future. This is not intended to be a comprehensive review of ethical issues arising in clinical research, ${ }^{11}$ but rather an application of the foundational requirements of research ethics to some of the most important and common challenges within the field of neurologic clinical research.

\section{Historical concerns: IRB review}

IRBs are panels of subject matter experts and lay people established by institutions conducting research on human 
Table Ethical principles for clinical research

\begin{tabular}{|c|c|c|}
\hline Requirement & Summary & Examples of violations \\
\hline Social value & $\begin{array}{l}\text { A study must have the potential to improve human health or } \\
\text { meaningfully increase society's knowledge of human biology }\end{array}$ & $\begin{array}{l}\text { A placebo-controlled trial of a "me-too" medication, i.e., no } \\
\text { safer, more effective, or cheaper than existing medications } \\
\text { for the same illness }\end{array}$ \\
\hline Scientific validity & $\begin{array}{l}\text { A study must use accepted scientific methodology to produce valid } \\
\text { and reproducible results }\end{array}$ & $\begin{array}{l}\text { A study that uses unblinded and biased assessments of } \\
\text { outcomes that systematically favor the study drug }\end{array}$ \\
\hline $\begin{array}{l}\text { Fair participant } \\
\text { selection }\end{array}$ & $\begin{array}{l}\text { Study sites, populations, and participants must be selected based } \\
\text { primarily on scientific criteria and vulnerable populations must not } \\
\text { be targeted or excluded in clinical studies }\end{array}$ & $\begin{array}{l}\text { A study that excludes female participants without an explicit } \\
\text { and valid scientific rationale }\end{array}$ \\
\hline $\begin{array}{l}\text { Favorable } \\
\text { risk-benefit ratio }\end{array}$ & $\begin{array}{l}\text { Risks to participants must be minimized and potential benefits to } \\
\text { participants and society must exceed the risks }\end{array}$ & $\begin{array}{l}\text { A trial using a placebo control even though safe and effective } \\
\text { treatments are otherwise readily available to participants }\end{array}$ \\
\hline Independent review & $\begin{array}{l}\text { Clinical studies must be reviewed and approved by knowledgeable } \\
\text { individuals unaffiliated with the research }\end{array}$ & $\begin{array}{l}\text { A study conducted in a nation or institution where } \\
\text { institutional review board review is pro forma, with } \\
\text { guaranteed approval }\end{array}$ \\
\hline Informed consent & $\begin{array}{l}\text { Participants must be accurately informed of and understand the } \\
\text { purpose, risks, benefits, and alternatives of a clinical study, and } \\
\text { make an uncoerced decision whether or not to participate }\end{array}$ & $\begin{array}{l}\text { A study in which participants are not informed of existing } \\
\text { effective treatments outside the study }\end{array}$ \\
\hline $\begin{array}{l}\text { Respect for enrolled } \\
\text { and potential } \\
\text { participants }\end{array}$ & $\begin{array}{l}\text { Potential and enrolled participants must be treated respectfully, } \\
\text { with attention to and protection of their privacy and interests } \\
\text { throughout the course of the study }\end{array}$ & $\begin{array}{l}\text { A study of a genetic test in which identifiable results can be } \\
\text { obtained by employers, law enforcement, or others }\end{array}$ \\
\hline
\end{tabular}

Principles of ethical research derived from the Nuremberg Code, the Declaration of Helsinki, the Belmont Report, and the US Common Rule. Originally developed by Emanuel et al. ${ }^{8}$

participants and mandated by the DHHS Common Rule. They are intended to protect the rights and welfare of research participants by providing unbiased independent review of clinical research. Data safety monitoring boards fulfill a similar function through independent review of study data once research is underway as an added layer of human participant protection in large randomized trials. Some scientific, medical, ethical, and legal scholars have raised concerns about potential impediments to research imposed by the Common Rule's requirement for IRB review. ${ }^{12-15}$ Schneider ${ }^{12}$ makes an extreme critique of IRB review in The Censor's Hand: The Misregulation of Human-Subject Research, arguing that the risks to participants in most clinical research are minimal, that the burdens imposed on clinical research by IRB review are severe, and that the overall balance between costs and benefits favors the elimination of IRB review. The AAN is sensitive to the logistical and temporal obligations imposed by IRB review on researchers. The AAN is also mindful of the high degree of variability between IRBs in the application of federal regulations, the time needed to review studies, and the decisions rendered. ${ }^{16}$ This variability can greatly increase the uncertainty and difficulty of obtaining IRB approval for clinical research, especially in multicenter studies.

The AAN believes that the excellent safety record of modern biomedical research in the United States, which Schneider and others cite as an argument against the need for IRB review, is actually attributable in large part to the Common Rule's requirement for rigorous IRB review of research protocols. Given the potential for conflicts of interest inherent in clinical research and the primary obligation to protect the safety of human participants, the AAN strongly endorses the principle of independent review as a necessary procedural safeguard. This is essential to ensure the implementation of the other principles of ethical clinical research. IRBs are the best established and proven means to ensure independent review. Alternative mechanisms (e.g., public review through online registries) could eventually emerge and supplant the need for IRBs. For now, the AAN believes that eliminating IRBs in the absence of an adequate surrogate would undermine the ethical foundation of clinical research and the safety of research participants. Relying on frequently vulnerable study participants to police violations through civil legal action, as Schneider and other radical critics of IRBs propose, would fail to avert preventable harms and would place an extraordinary and unjustifiable burden on study participants.

While IRBs remain critical to the independent review and ethical practice of clinical research, reforms to IRBs are currently being implemented by the NIH and others to (1) minimize impediments imposed by IRBs that are unlikely to improve the safety of human participants, (2) make the boards more responsive to appeals and criticism, and (3) increase standardization and consistency between IRBs. These reforms potentially diminish administrative burden without compromising research participant safety, and accord with the DHHS 2017 amendment to the Common Rule. ${ }^{17}$ As previously discussed, the Common Rule is a federal policy providing standardized protections for human research participants in federally funded research. It applies to 16 signatory federal departments and agencies, and to researchers and research institutions that receive funding from those 
agencies. ${ }^{18}$ Signatory departments and agencies include DHHS, the Department of Defense, the Department of Labor, the Department of Energy, the Department of Commerce, the National Aeronautics and Space Administration, and others. The Department of Homeland Security, the Central Intelligence Agency, and others have not actually signed the Common Rule but adhere to its requirements. In practice, almost all academic institutions in the United States require their researchers to abide by the Common Rule regardless of the source of research funding. The Common Rule main elements include the following:

- $\quad$ Requirements for IRB membership, function, operations, review, and record-keeping

- $\quad$ Requirements for obtaining and documenting informed consent

- Requirements for additional protections for vulnerable populations including prisoners, pregnant women, fetuses, children, and other participants lacking decision-making capacity

The 2017 amendment to the Common Rule is intended to reduce logistical burden and improve participant protection by mandating review of most multisite trials by a single central IRB, rather than by multiple parallel IRBs. A central IRB is the sole IRB of record that provides ethical review for all sites participating together in one or more multisite studies. The amendment further reduces regulatory burdens (and allows IRBs to focus on higher-risk studies) by creating new exemptions from IRB review for low-risk studies and by eliminating the need for continuing IRB review in others. In addition, the amendment creates the option for participants to grant broad consent for the use of their information and biological samples in future studies. Some IRBs are reporting increased regulatory burdens and delays under the newly implemented revised Common Rule, which may lead to the need for further amendments. Generally, the AAN endorses reforms directed at simplifying review of multisite studies under central IRBs, reducing review of low-risk studies, and giving research participants options for broad consent to future studies. The AAN also supports IRBs' use of publicly available ethics checklists such as the Harvard Multi-Regional Clinical Trials Center ethics toolbox. ${ }^{19}$ This ensures that the criteria for IRB review are available to all stakeholders, and are consistent between studies and between IRBs. Finally, the AAN encourages mechanisms to allow appeals when IRB rulings conflict with the views of independent reviewers.

\section{Historical concerns: Equitable research participant inclusion}

The research and bioethics communities increasingly recognize an ethical problem in participant selection: broad segments of the population, including women, minority races and ethnicities, children, and the elderly, are systematically underrepresented in clinical research. ${ }^{20-24}$ Such underrepresentation limits the generalizability or external validity of study results and diminishes the long-term benefits that underrepresented populations obtain from research. Therefore, systematic underrepresentation-when not justified by study-specific scientific requirements or populationspecific risks - conflicts with the principles of fair representation, scientific validity, and social value. Yet systematic reviews show that large populations often are excluded from clinical trials with little or no justification. ${ }^{25,26}$

For these reasons, the AAN endorses the NIH requirements that (1) clinical studies include both sexes and minority races and ethnicities unless there are specific valid scientific or ethical reasons not to do so in a given study; (2) clinical trials include sufficient numbers of participants to allow for a valid analysis of whether women or minority participants are affected differently than other participants; and (3) all NIHfunded trials submit these subgroup analyses to ClinicalTrials.gov. ${ }^{27}$ The AAN also endorses the NIH requirement that clinical studies include individuals of all ages (including children and older adults) unless there are specific scientific or ethical reasons not to do so in a given study. ${ }^{28}$ The AAN recommends that, when possible, nonNIH-funded clinical neuroscience studies also follow these guidelines. Recognizing that pilot studies and studies of rare neurologic diseases cannot realistically conform with this requirement, the $\mathrm{AAN}$ recommends that, at minimum, clinical neuroscience research not exclude or restrict participants by sex, race, ethnicity, or age unless there is a scientific or ethical reason specific to that study. In addition, where possible, participant recruitment should take place at community hospitals as well as academic centers, to promote geographic and socioeconomic diversity.

\section{Historical concerns: Cognitive impairment in research participants}

Clinical neuroscience often involves the study of diseases that cause temporary or permanent cognitive impairment. Many participants with neurologic and psychiatric diseases have impaired or nonexistent capacity to engage in the informed consent process, and capacity may fluctuate over time in disorders such as epilepsy and dementia. Capacity screening instruments have been developed and validated, and should be used whenever a study's inclusion criteria encompass participants with disorders that place them at risk. ${ }^{29}$ The results of such screening instruments must be confirmed by a qualified clinician.

The principle of informed consent requires the provision of accurate information about the purpose, methods, risks, benefits, and alternatives to the study and an uncoerced decision by a participant with decision-making capacity. ${ }^{8} \mathrm{De}$ cisional capacity includes 4 abilities: (1) understanding (of the basic facts about the decision including risks, benefits, and alternatives), (2) appreciation (recognition that the facts apply to oneself), (3) reasoning (an ability to logically manipulate information, as in weighing risks and benefits), and (4) the expression of choice (the ability to articulate a choice consistently over time). ${ }^{30}$ Importantly, decisional capacity is recognized to exist on a continuum, depending on the 
complexity and importance of a decision, and not to be a dichotomous all-or-nothing characteristic.

When impaired decision-making capacity precludes direct fulfillment of the requirement for informed consent, a legally authorized representative may make the decision on the participant's behalf. The 2017 amendment to the Common Rule specifies that, where state law does not specify rules for surrogate decision-making about research, surrogates for medical decision-making can also be considered surrogates for decisions about clinical research (this is the case in most states). ${ }^{18}$ The surrogate should use a substituted judgment standard, making the decision based on the participant's historical beliefs and values, as the surrogate believes the participant would, were the participant able to undertake the informed consent process. ${ }^{31}$ IRBs may require additional safeguards, such as independent consent monitors, depending on the degree of cognitive incapacity and the study's riskbenefit ratio and complexity. ${ }^{32}$ In developing such safeguards, IRBs should make every effort to fully protect participants with dementia and other cognitive impairments, while minimizing impediments to studies of these important conditions. Similarly, in developing safeguards for pediatric participants, IRBs should endeavor to balance rigorous protection for children participating in research, with the minimization of impediments to clinical research on pediatric neurologic disorders. Of note, the informed consent process can be cognitively and emotionally demanding, and every effort should be made to ensure participants' and surrogate decision-makers' comprehension. In addition, where possible, researchers should consider disclosing relevant conflicts of interest during the informed consent process.

In emergency settings, where time constraints prohibit the informed consent process with a legally authorized representative, where the research could not otherwise be conducted, where there is a possibility of direct benefit to the prospective participant, and where there is prior assent from community representatives, IRBs may grant an exception from informed consent (EFIC). ${ }^{33,34}$ EFIC typically requires prior consultation with and education for the entire community in which the research is to be conducted.

\section{Current controversies: International clinical research}

International clinical research in low- and middle-income countries (LMICs) has expanded dramatically over the last 2 decades, while the number of trials in the United States and Western Europe has declined. ${ }^{35,36}$ Some of the newly globalized clinical research targets public health concerns specific to or shared by LMICs, areas of research that have historically received disproportionately low rates of attention and funding. However, some globalized clinical research is conducted by pharmaceutical, biotechnology, and device companies developing products intended for sale in high-income countries (HICs). This raises potential ethical concerns. First there is the potential concern that some companies may be motivated to globalize research due to less stringent ethical oversight (as well as lower study costs). This may entail a violation of the requirement for independent review, which potentially undermines the implementation of all other ethical requirements as discussed in the section on IRB review. Similarly, there is a concern that some individuals in LMICs who otherwise lack access to health care may feel coerced to enroll in a clinical study to obtain otherwise unobtainable but needed health care for themselves or their family members. This represents a potential failure of the principle of informed consent due to a coercive influence (or the participant's perception of a coercive influence). Informed consent, like the principle of independent review, is a critical procedural safeguard. Third, there is a concern about the potential exploitation of LMIC research participants to obtain data for use in products for HICs that will not generally be available to the LMIC populations who bore the risks of the research. This represents a potential failure to fulfill the fair participant selection requirement. Finally, there is a concern that the interests and values of research participants in LMICs are not always sufficiently reflected in studies that are designed, funded, and published in HICs, by HIC researchers. This is at heart a concern about the principle of respect for potential and enrolled participants.

Many ethical guidelines have been developed for international clinical research that attempt to address the potential ethical concerns outlined above. These include the WMA's Declaration of Helsinki, the international ethical guidelines issued by the Council of International Organisations for Medical Sciences (CIOMS), and the International Conference on Harmonisation of Technical Requirements for Registration of Pharmaceuticals for Human Use's Guideline for Good Clinical Practice (ICH-GCP).$^{37}$ Although there are broad areas of agreement (e.g., research populations should have a reasonable likelihood of benefitting from the results of clinical research), these guidelines are not legally binding and provide conflicting guidance regarding some specific issues. ${ }^{37,38}$

The AAN endorses ongoing international clinical research, crucial to improving health care in LMICs, but stipulates that the research community must act to ensure the safety and dignity of human participants who participate in clinical research in LMICs. To achieve this end in a systematic and lasting manner, the AAN favors pursuit of unified guidelines for international research through international organizations such as the WMA and CIOMS. Unified guidelines should incorporate lessons learned from existing guidelines such as the Declaration of Helsinki and the ICH-GCP, and the input of broad representation from both HICs and LMICs. The AAN further recommends that unified guidelines utilize fundamental ethical principles like those detailed in the Belmont Report and summarized in the 7 requirements detailed by Emanuel.

\section{Current controversies: Replication crisis}

The replication crisis refers to the increasingly recognized phenomenon of peer-reviewed and widely cited studies that 
demonstrate statistically significant results that cannot be reproduced by other researchers. ${ }^{39,40}$ Some failures of replication are likely due to intervening scientific and technological advances, failures to perfectly reproduce original study conditions, and the use of insufficient sample sizes in replicated studies. More recent replication efforts have addressed these issues by obtaining detailed review and approval from the scientists who conducted the original studies, and by using significantly larger sample sizes than the original studies, and yet have reproduced significant results in fewer than half of replicated studies. ${ }^{41}$ Using the framework of Emanuel's 7 principles, the replication crisis suggests possible violations of the requirements for scientific validity and social value in clinical research. Publication bias, and specifically the selective reporting of positive studies or studies that report a statistically significant difference or effect, is cited as one of the key contributors to the replication crisis. ${ }^{42}$ A system of clinical studies that produces consistently biased results lacks scientific validity. It also has diminished potential to improve human health or increase society's knowledge of human biology, and therefore has diminished social value. Within Emanuel's summarizing framework for ethical clinical research, these violations undermine the ethical justification for the social resources devoted to such studies and especially for the risks undertaken by research participants.

Although the field of psychology has received the most attention for failures of reproducibility, ${ }^{43}$ replication failures have occurred across most fields, including clinical neuroscience. ${ }^{44-46}$ To address the replication crisis, the AAN endorses a number of measures directed at improving the scientific validity of clinical neuroscience, as part of the ethical protection of research participants. Since 2017, the DHHS and NIH have required that all NIH-funded clinical trials, excluding phase I trials and feasibility studies, must be preregistered with ClinicalTrials.gov and trial findings reported in a timely manner. ${ }^{47}$ Compliance provides the public with accurate and current trial information, and also reduces publication bias, which is thought to contribute to low replicability rates. The AAN endorses this rule. Given the ongoing development of public registries and the lack of consensus regarding the registration of observational studies, the AAN does not at this time endorse a requirement that observational studies be preregistered, but recommends that registration of interventional and observational studies be considered when possible, regardless of funding source. In addition, we recommend whenever feasible the open sharing of clinical neuroscience data, research protocols, statistical analyses, and results in publicly accessible repositories such as Open Science Framework (osf.io) or the Registry of Research Data Repositories (re3data.org). This allows public review and reanalysis of data, helping to detect and eliminate bias that escapes the traditional peer review process. Systematic reviews comparing published studies to protocols commonly identify evidence of selective reporting of outcomes within published studies, a source of bias that can be detected and reduced through the open sharing of research protocols. ${ }^{48-51}$ The AAN also recommends the use of peer-reviewed checklists for the reporting of all clinical neuroscience studies, such as the Consolidated Standards of Reporting Trials 2010 checklist for randomized trials (consort-statement.org) and the Strengthening the Reporting of Observational Studies in Epidemiology checklist for observational studies (strobestatement.org). In keeping with Ioannidis ${ }^{52}$ and the New England Journal of Medicine and Neurology ${ }^{\circledR}$ guidelines for statistical reporting, the AAN endorses supplementing or replacing reported $p$ values with measures of effect size or association and measures of uncertainty (such as $95 \%$ confidence intervals), when the statistical analysis plan does not prespecify methods to adjust for multiple tests. ${ }^{52,53}$ Finally, the AAN endorses the funding and publication of replication studies. These endorsements should not be construed as a critique of the peer review system. The AAN recognizes that peer review has played and continues to play a critical role in ensuring the scientific validity and ethical conduct of clinical research. Rather, this position statement identifies enhancements by which peer review may be further strengthened.

\section{Imminent ethical issues: Genetic research}

The burgeoning field of genetic clinical neuroscience raises a host of new ethical issues. Genetic testing, even in the absence of active genetic modifications, can raise important ethical concerns. The depth and breadth of sensitive information collected during clinical research has expanded dramatically as whole exome and whole genome sequencing have become commonplace. This may have the consequence of incidentally identifying unanticipated genetic information, wholly unrelated to the research, that nonetheless has potential adverse implications for both the patient and the family. Approximately $2 \%$ of apparently healthy adults of European descent undergoing whole exome testing are found to have genetic variations that are disease-causing or likely to be disease-causing, for which medical intervention is possible to avert or ameliorate the effects of the disease. ${ }^{54}$ Such results are said to be actionable. Currently, many studies do not divulge genetic testing results to participants at any time even when they are actionable. Genetic testing can also affect family members by inadvertently exposing mutations in asymptomatic individuals at risk who had previously chosen to avoid this knowledge (or had not consented to testing) and who might be participants to psychological harm or discrimination. Similarly, genetic testing can affect familial relationships by incidentally revealing misattributed paternity. The risk of incidental genetic findings may be particularly important for pediatric participants and others who lack capacity. Such participants may find their future lives altered or constrained in important ways as a result of parents' or guardians' decisions to enroll them in research involving genetic testing.

The principle of informed consent requires that such risks be outlined during the consent process. We recommend that expert panels establish and regularly update consensus listings 
of actionable genetic testing results, with the ultimate objective of providing participants with an option to be informed-or not-of incidentally discovered actionable results during the informed consent process prior to genetic testing. ${ }^{55}$ The end goal for these expert panels would be to develop and maintain updated formal guidelines for the disclosure of actionable genetic test results, likely through referral of affected research participants to board-certified genetic physicians or genetic counselors. Similarly, identification of the boundaries for the future use of stored genetic data should be specified in the informed consent process. The principle of respect for research participants requires that genetic data be kept confidential and secure, and the 2017 amendment to the DHHS Common Rule provides updated rules for the protection of participant data. ${ }^{17}$ In addition to providing physical and technological safeguards for genetic data, the AAN recommends that clinical researchers collecting whole exome or whole genome data obtain an NIH certificate of confidentiality. This document serves to protect sensitive study data including genetic information from legal discovery regardless of jurisdiction or nature of the proceeding (civil or criminal). ${ }^{56}$

Looking into the near future, research involving genetic modifications of plant, animal, and human somatic and germinal cells, via CRISPR/Cas9 and other gene editing technologies, will present cascading ethical quandaries. It appears possible that future gene editing research could violate the requirements for social value, a favorable risk-benefit ratio, or informed consent. Ethical challenges are evolving in parallel with rapidly developing gene editing technologies as new applications are conceived and explored. A full review of these ethical issues is beyond the scope of this position paper. We highlight areas of ethical concern and endorse the ongoing efforts of the NIH, the US National Academy of Sciences, the Chinese Academy of Sciences, and the Royal Society of the United Kingdom to develop a framework for ethical assessment and regulation of gene editing research. ${ }^{18}$

Even when limited to nonhuman genomes, as in the case of genetically modifying mosquitoes to prevent malaria transmission, gene editing offers the potential to generate ecological disequilibrium - particularly through the use of gene drive technology. Gene drives are a genetic engineering technique that involves the insertion of self-propagating genetic sequences that are then transmitted to all offspring across all subsequent generations. Geneticists typically construct these self-propagating gene drives using a payload gene combined with a gene for an endonuclease like Cas9 that cuts wild-type DNA at a specific target. The cell's natural DNA repair system then copies the entire gene drive (including the endonuclease gene and the payload gene) into the cleaved wild-type chromosome during the repair process, replicating the gene drive. Such technology promotes the rapid spread of the payload gene through an entire population over the course of multiple generations. Species-wide changes can then occur either intentionally or unintentionally through the occurrence of off-target mutations. These off-target mutations involve the accidental insertion of the novel genetic sequence in an unintended location in the genome, potentially causing the deactivation or modification of unintended genes, and appear to be more frequent in complex genomes. ${ }^{57}$ Species-wide genetic changes could cause extinction or uncontrolled overgrowth and ecological disequilibrium. This could potentially present a serious ecological threat that would violate the ethical requirements for social value and especially a favorable risk-benefit ratio. This potential violation of ethical principles may justify national or international regulation of gene editing and particularly gene drive research.

When applied to human somatic or germ cells, gene editing also introduces the additional risk of unintended consequences to individual participants through imperfectly understood genotype-phenotype interactions, or through offtarget mutations in which the new genetic sequence is accidently inserted in an incorrect location. Gene editing in humans also introduces ethical questions about enhancement (rendering the participant not merely healthier but taller, smarter, stronger, or in some other way "superior" to "normal" human functioning). Whether genetic technology should ever be used for enhancement, and if so under what conditions, is a question that ethicists and geneticists will need to address in the near future before reliable genetic enhancement becomes available. Finally, human germ cells, unlike somatic cells, are involved in transmission of genes to offspring, and genetic editing of germ cells can extend the effects and the risks of genetic research beyond current participants to future generations. This greatly amplifies the risks from unexpected genotype-phenotype interactions and off-target mutations, extending potential risks to entire families, populations, and the human species. In addition, genetic modifications of germ cells may violate the requirements of informed consent since affected future generations would have no choice about participation in the study. For these reasons, the AAN endorses a moratorium on human germline editing until the research community establishes a better understanding of the risks entailed, and until a framework for international oversight and regulation is established. ${ }^{58}$

We hope that the application of a principle-based ethical framework will facilitate and lend greater consistency and fairness to ethical research design, implementation, and analysis. From well-established ethical issues like the inclusion of cognitively impaired research participants to areas with actively evolving ethical challenges like CRISPR-Cas9 gene editing, the application of a principle-based framework offers the potential for a degree of transparency and consistency that is sometimes lacking in modern ethics oversight of clinical research.

\section{Acknowledgment}

The authors thank the members of the AAN Clinical Research Subcommittee for input on earlier drafts of this manuscript. 
The following individuals participated in the development of this position statement as members of the Ethics, Law, and Humanities Committee, a joint committee of the AAN, American Neurological Association, and Child Neurology Society: Katharina M. Busl, Winston Chiong, Salvador CruzFlores, Charles C. Flippen, William D. Graf, Matthew Kirschen, Dan Larriviere, Julie Kurek, Ariane Lewis, Michael Rubin, Ericka P. Simpson, Barney J. Stern, Lynne Taylor, and Amy Tsou. Sarah Bird Nelson and Karen Kasmirski facilitated discussion and approval of this report as AAN staff.

\section{Study funding}

No targeted funding reported.

\section{Disclosure}

B. Tolchin received research funding from a US Veterans Administration (VA) VISN1 Career Development Award, the VA Pain Research, Informatics, Multimorbidities, and Education (PRIME) Center of Innovation, and the C.G. Swebilius Trust; and received honoraria from Columbia University Medical Center, the International League against Epilepsy, and the American Academy of Neurology. R. Conwit and L.G. Epstein report no relevant disclosures. J.A. Russell serves on a Data Monitoring Committee for Cytokinetics for Cy 5022. Go to Neurology.org/ $\mathrm{N}$ for full disclosures.

\section{Disclaimer}

This article does not represent the official views of the National Institute of Neurologic Disorders and Stroke (NINDS), the $\mathrm{NIH}$, or any part of the US Federal Government. No official support or endorsement of this article by NINDS or NIH is intended or should be inferred.

\section{Publication history}

Received by Neurology October 23, 2019. Accepted in final form January 7, 2020.

\section{Appendix Authors}

\begin{tabular}{|c|c|c|}
\hline Name & Location & Contribution \\
\hline $\begin{array}{l}\text { Benjamin } \\
\text { Tolchin, } \\
\text { MD, MS }\end{array}$ & $\begin{array}{l}\text { Yale School of Medicine, } \\
\text { New Haven, CT }\end{array}$ & $\begin{array}{l}\text { Document concept and } \\
\text { design, literature search, } \\
\text { drafting the manuscript, } \\
\text { revision for intellectual } \\
\text { content }\end{array}$ \\
\hline
\end{tabular}

Robin $\quad$ NIH, Bethesda, MD
Conwit,
MD

Conwit

Overall project supervision, document concept and design, literature search, government updates and perspectives, revision for intellectual content

\begin{tabular}{lll}
\hline $\begin{array}{l}\text { Leon G. } \\
\text { Epstein, } \\
\text { MD }\end{array}$ & $\begin{array}{l}\text { Northwestern University } \\
\text { Feinberg School of } \\
\text { Medicine, Chicago, IL }\end{array}$ & $\begin{array}{l}\text { Revision for intellectual } \\
\text { content }\end{array}$ \\
\hline James & Lahey Hospital and Medical & $\begin{array}{l}\text { Revision for intellectual } \\
\text { Russell, }\end{array}$ \\
Co, MS & Center, Burlington, MA & \\
\hline
\end{tabular}

\section{References}

1. Henderson GE, Churchill LR, Davis AM, et al. Clinical trials and medical care: defining the therapeutic misconception. PLoS Med 2007;4:e324.

2. Weindling P, von Villiez A, Loewenau A, Farron N. The victims of unethical human experiments and coerced research under national socialism. Endeavour 2016;40:1-6.

3. Paul C, Brookes B. The rationalization of unethical research: revisionist accounts of the Tuskegee Syphilis Study and the New Zealand "unfortunate experiment." Am J Public Health 2015; 105:e12-19.

4. Zimbardo PG. On the ethics of intervention in human psychological research: with special reference to the Stanford Prison Experiment. Cognition 1973;2:243-256.

5. Wilson ST, Stanley B. Ethical concerns in schizophrenia research: looking back and moving forward. Schizophr Bull 2006;32:30-36.

6. Algahtani H, Bajunaid M, Shirah B. Unethical human research in the field of neuroscience: a historical review. Neurol Sci 2018;39:829-834.

7. The Ethics and Humanities Subcommittee of the American Academy of Neurology. Ethical issues in clinical research in neurology: advancing knowledge and protecting human research subjects. Neurology 1998;50:592-595.

8. Emanuel EJ, Wendler D, Grady C. What makes clinical research ethical? JAMA 2000; 283:2701-2711.

9. Emanuel EJ. Ethical and Regulatory Aspects of Clinical Research: Readings and Commentary. Baltimore: Johns Hopkins University Press; 2003.

10. Emanuel EJ, Abdoler E, Stunkel L. Research Ethics: How to Treat People Who Participate in Research. Bethesda: National Institutes of Health; 2010.

11. Emanuel EJ. The Oxford Textbook of Clinical Research Ethics. Oxford: Oxford University Press; 2011.

12. Schneider C. The Censor's Hand: The Misregulation of Human-Subject Research. Cambridge: The MIT Press; 2015.

13. Schrag ZM. Ethical Imperialism: Institutional Review Boards and the Social Sciences, 1965-2009. Baltimore: Johns Hopkins University Press; 2010.

14. Klitzman R. The Ethics Police? The Struggle to Make Human Research Safe. Oxford: Oxford University Press; 2015.

15. Pinker S. Enlightenment Now: The Case for Reason, Science, Humanism, and Progress. New York: Viking, an imprint of Penguin Random House LLC; 2018.

16. Abbott L, Grady C. A systematic review of the empirical literature evaluating IRBs what we know and what we still need to learn. J Empir Res Hum Res Ethics 2011;6: 3-19.

17. Menikoff J, Kaneshiro J, Pritchard I. The common rule, updated. N Engl J Med 2017; 376:613-615.

18. US Department of Health and Human Services. Federal policy for the protection of human subjects: final rule. Fed Regist 2017;82:7149.

19. Li RH, Wacholtz MC, Barnes M, et al. Incorporating ethical principles into clinical research protocols: a tool for protocol writers and ethics committees. J Med Ethics 2016;42:229-234

20. Murthy VH, Krumholz HM, Gross CP. Participation in cancer clinical trials: race-, sex-, and age-based disparities. JAMA 2004;291:2720-2726.

21. Kwiatkowski K, Coe K, Bailar JC, Swanson GM. Inclusion of minorities and women in cancer clinical trials, a decade later: have we improved? Cancer 2013;119:2956-2963.

22. Ranganathan M, Bhopal R. Exclusion and inclusion of nonwhite ethnic minority groups in 72 North American and European cardiovascular cohort studies. PLoS Med 2006;3:e44.

23. Bartlett C, Doyal L, Ebrahim S, et al. The causes and effects of socio-demographic exclusions from clinical trials. Health Technol Assess 2005;9:iii-iv, ix-x, 1-152.

24. Hurria A, Dale W, Mooney M, et al. Designing therapeutic clinical trials for older and frail adults with cancer: U13 conference recommendations. J Clin Oncol 2014;32: 2587-2594.

25. Cherubini A, Oristrell J, Pla X, et al. The persistent exclusion of older patients from ongoing clinical trials regarding heart failure. Arch Intern Med 2011;171:550-556.

26. Cruz-Jentoft AJ, Carpena-Ruiz M, Montero-Errasquin B, Sanchez-Castellano C, Sanchez-Garcia E. Exclusion of older adults from ongoing clinical trials about type 2 diabetes mellitus. J Am Geriatr Soc 2013;61:734-738.

27. National Institutes of Health. Amendment: NIH Policy and Guidelines on the Inclusion of Women and Minorities as Subjects in Clinical Research. Bethesda: National Institutes of Health; 2017.

28. National Institutes of Health. Revision: NIH Policy and Guidelines on the Inclusion of Individuals Across the Lifespan as Participants in Research Involving Human Subjects. Bethesda: National Institutes of Health; 2017.

29. Jeste DV, Palmer BW, Appelbaum PS, et al. A new brief instrument for assessing decisional capacity for clinical research. Arch Gen Psychiatry 2007;64:966-974.

30. Appelbaum PS. Clinical practice: assessment of patients' competence to consent to treatment. N Engl J Med 2007;357:1834-1840.

31. Beauchamp T, Childress J. Principles of Biomedical Ethics, 7th ed. New York: Oxford University Press; 2012.

32. Chen DT, Miller FG, Rosenstein DL. Enrolling decisionally impaired adults in clinical research. Med Care 2002;40:V20-V29.

33. National Institutes of Health. Waiver of informed consent requirements in certain emergency research. Fed Regist 1996;61:51531-51533.

34. Bateman BT, Meyers PM, Schumacher HC, Mangla S, Pile-Spellman J. Conducting stroke research with an exception from the requirement for informed consent. Stroke 2003;34:1317-1323.

35. George M, Selvarajan S, Dkhar SA, Chandrasekaran A. Globalization of clinical trials where are we heading? Curr Clin Pharmacol 2013;8:115-123.

36. Glickman SW, McHutchison JG, Peterson ED, et al. Ethical and scientific implications of the globalization of clinical research. N Engl J Med 2009;360:816-823. 
37. Weigmann $\mathrm{K}$. The ethics of global clinical trials: in developing countries, participation in clinical trials is sometimes the only way to access medical treatment: what should be done to avoid exploitation of disadvantaged populations? EMBO Rep 2015;16:566-570.

38. World Medical Association. World Medical Association Declaration of Helsinki: ethical principles for medical research involving human subjects. JAMA 2013;310:2191.

39. Schmidt S. Shall we really do it again? The powerful concept of replication is neglected in the social sciences. Rev Gen Psychol 2009;13:90-100.

40. Baker M. 1,500 scientists lift the lid on reproducibility. Nature 2016;533:452-454.

41. Klein RA, Vianello M, Hasselman F, et al. Many Labs 2: investigating variation in replicability across samples and settings. Adv Methods Pract Psychol Sci 2018;1:443-490.

42. Ioannidis JP. Why most published research findings are false. PLoS Med 2005;2:e124.

43. Open Science Collaboration. Psychology: estimating the reproducibility of psychological science. Science 2015;349:aac4716.

44. Boekel W, Wagenmakers EJ, Belay L, Verhagen J, Brown S, Forstmann BU. A purely confirmatory replication study of structural brain-behavior correlations. Cortex 2015; 66:115-133.

45. Poldrack RA, Baker CI, Durnez J, et al. Scanning the horizon: towards transparent and reproducible neuroimaging research. Nat Rev Neurosci 2017;18:115-126.

46. Button KS, Ioannidis JP, Mokrysz C, et al. Power failure: why small sample size undermines the reliability of neuroscience. Nat Rev Neurosci 2013;14:365-376.

47. US Department of Health and Human Services. Clinical trials registration and results information submission. Fed Regist 2016;81:64981-65157.

48. Chan AW, Hrobjartsson A, Haahr MT, Gotzsche PC, Altman DG. Empirical evidence for selective reporting of outcomes in randomized trials: comparison of protocols to published articles. JAMA 2004;291:2457-2465.
49. Dwan K, Altman DG, Clarke M, et al. Evidence for the selective reporting of analyses and discrepancies in clinical trials: a systematic review of cohort studies of clinical trials. PLoS Med 2014;11:e1001666.

50. Chan AW, Pello A, Kitchen J, et al. Association of trial registration with reporting of primary outcomes in protocols and publications. JAMA 2017;318:1709-1711.

51. van den Bogert CA, Souverein PC, Brekelmans CTM, et al. Primary endpoint discrepancies were found in one in ten clinical drug trials. Results of an inception cohort study. J Clin Epidemiol 2017;89:199-208.

52. Ioannidis JPA. The proposal to lower P value thresholds to .005. JAMA 2018;319: 1429-1430.

53. Harrington D, D'Agostino RB Sr, Gatsonis C, et al. New guidelines for statistical reporting in the journal. N Engl J Med 2019;381:285-286.

54. Amendola LM, Dorschner MO, Robertson PD, et al. Actionable exomic incidental findings in 6503 participants: challenges of variant classification. Genome Res 2015; 25:305-315.

55. Green RC, Berg JS, Grody WW, et al. ACMG recommendations for reporting of incidental findings in clinical exome and genome sequencing. Genet Med 2013;15: 565-574

56. National Institutes of Health. Certificates of confidentiality (COC): human subjects [online]. Available at: grants.nih.gov/policy/humansubjects/coc.htm. Accessed December 12, 2019.

57. Zhang XH, Tee LY, Wang XG, Huang QS, Yang SH. Off-target effects in CRISPR/ Cas9-mediated genome engineering. Mol Ther Nucleic Acids 2015;4:e264.

58. Baltimore D, Berg P, Botchan M, et al. Biotechnology: a prudent path forward for genomic engineering and germline gene modification. Science 2015;348:36-38.

\section{AAN Online Learning}

Browse a variety of online CME, self-assessment, and other learning activities to suit your wide-ranging interests and learning styles. Visit AAN.com/Learn.

\section{Get NeuroReady!}

Preparing for the neurology boards? Up for recertification? Or just looking for a comprehensive review and update in neurology? Get ready with the AAN's convenient online courses-now with new names! Choose from NeuroReady: Board Prep Edition or NeuroReady: Continuing Certification Edition and get ready to review, self-assess, and succeed. Visit AAN.com/NeuroReady.

\section{Did You Know...}

... you can browse by subspecialty topics on Neurology.org?

Go to: Neurology.org and click on "Topics" in the top navigation bar. 


\title{
Neurology
}

\begin{abstract}
AAN position statement: Ethical issues in clinical research in neurology
Benjamin Tolchin, Robin Conwit, Leon G. Epstein, et al.
\end{abstract}

Neurology 2020;94;661-669 Published Online before print March 16, 2020

DOI 10.1212/WNL.0000000000009241

This information is current as of March 16, 2020

\begin{tabular}{|c|c|}
\hline $\begin{array}{l}\text { Updated Information \& } \\
\text { Services }\end{array}$ & $\begin{array}{l}\text { including high resolution figures, can be found at: } \\
\text { http://n.neurology.org/content/94/15/661.full }\end{array}$ \\
\hline References & $\begin{array}{l}\text { This article cites } 46 \text { articles, } 8 \text { of which you can access for free at: } \\
\text { http://n.neurology.org/content/94/15/661.full\#ref-list-1 }\end{array}$ \\
\hline Citations & $\begin{array}{l}\text { This article has been cited by } 5 \text { HighWire-hosted articles: } \\
\text { http://n.neurology.org/content/94/15/661.full\#\#otherarticles }\end{array}$ \\
\hline Subspecialty Collections & $\begin{array}{l}\text { This article, along with others on similar topics, appears in the } \\
\text { following collection(s): } \\
\text { All Ethics in Neurology/Legal issues } \\
\text { http://n.neurology.org/cgi/collection/all_ethics_in_neurology_legal_iss } \\
\text { ues } \\
\text { Professional conduct and ethics } \\
\text { http://n.neurology.org/cgi/collection/professional_conduct_and_ethics }\end{array}$ \\
\hline Permissions \& Licensing & $\begin{array}{l}\text { Information about reproducing this article in parts (figures,tables) or in } \\
\text { its entirety can be found online at: } \\
\text { http://www.neurology.org/about/about_the_journal\#permissions }\end{array}$ \\
\hline Reprints & $\begin{array}{l}\text { Information about ordering reprints can be found online: } \\
\text { http://n.neurology.org/subscribers/advertise }\end{array}$ \\
\hline
\end{tabular}

Neurology ${ }^{\circledR}$ is the official journal of the American Academy of Neurology. Published continuously since 1951, it is now a weekly with 48 issues per year. Copyright (C 2020 American Academy of Neurology. All rights reserved. Print ISSN: 0028-3878. Online ISSN: 1526-632X.

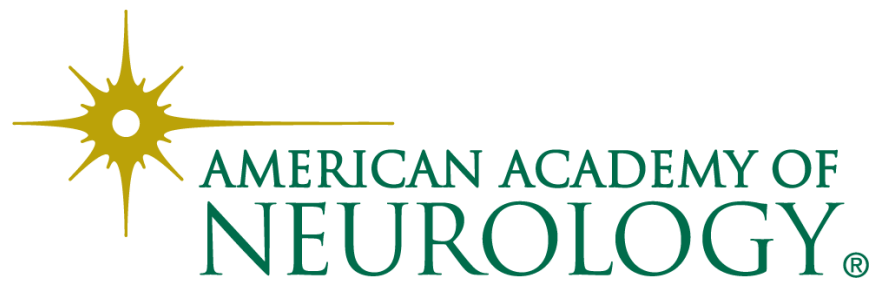

